PROCEEDINGS OF THE WORLD CONFERENCE ON OZONE THERAPY IN MEDICINE, DENTISTRY AND VETERINARY. ANCONA (ITALY). SEPTEMBER 22nd - 23rd - 24th, 2017

\title{
Applications of ozone therapy in urology [abstract]
}

\section{Sinan Ekici}

Turkey

\section{ABSTRACT}

\section{O OPEN ACCESS}

\section{Citation}

Ekici S. Applications of ozone therapy in urology [abstract]. Proceedings of The World Conference on Ozone Therapy in Medicine, Dentistry and Veterinary. Ancona (Italy). September 22nd - 23rd - 24th , 2017. J Ozone Ther. 2019;3(4):61. doi: 10.7203/ jo3t.3.4.2019.15543

Academic Editor Jose Baeza-Noci, School of Medicine, Valencia University, SPAIN

\section{Editor}

World Federation of Ozone Therapy, Bolgna, ITALY

\section{Received}

June 17, 2019

\section{Accepted}

December 08, 2019

Published

December 30, 2019

Intellectual Property

Sinan Ekici.

This is an open access article distributed under the terms of the Creative Commons Attribution License (CC BY 4.0), which permits unrestricted use, distribution, and reproduction in any medium, provided the original author and source are credited.

\section{Author Information} prof.sinanekici@gmail.com
Background. BacOzone therapy has been successfully used in various diseases for years. But, what about urological diseases? We used ozone therapy for the treatment of several urological diseases.

Material and Methods. From November 2016 up to now, we performed ozone therapy to treat intractable urethritis in 16 patients, chronic prostatitis/ chronic pelvic pain syndrome in 14 patients, chronic cystitis in 14 patients, erectile dysfunction in 21 patients. We used several criteria to test the effectiveness of the ozone therapy.

Results. According to the follow-up results, we obtained complete success in more than $90 \%$ of the patients, complains of almost $5 \%$ the patients relieved to tolerable degree. The remaining $5 \%$ was unresponsive to the ozone therapy. We did not experience of any complications.

Discussion. Our results showed that ozone can be used to treat intractable and challenging urological diseases without any complications. Determining the right patient to be treated with ozone safely, ozone application route and ozone dose are the most essential steps. Therefore, selection criteria of treatable patients must be clarified with increasing clinical experience soon.

Conclusion. This study summarizes and showed that different modalities of ozone therapy applications in various intractable or chronic urological diseases can be used successfully and safely.

\section{References}

1. Ekici S, Doğan Ekici Al, Öztürk G, Benli Aksungar F, Sinanoğlu O, Turan $G$, Lüleci N. Comparison of melatonin and ozone in the prevention of reperfusion injury following unilateral testicular torsion in rats. Urology. 2012;80(4):899-906.

2. Bayrak Ö, Erturhan S, Seckiner I, Erbagci A, Abdulkerim A Ustun A, and Karakok M. Chemical cystitis developed in experimental animals model: Topical effect of intravesical ozone application to bladder. Urol Ann. 2014;6(2):122-126. 